\title{
ÁREA VERDES URBANAS EM ANAURILÂNDIA-MS - ESTUDO E CASO
}

Letícia Pirola Maziero'; Sibila Corral de Arêa Leão Honda²

${ }^{1}$ Discente do curso de Arquitetura e Urbanismo da Universidade do Oeste Paulista - UNOESTE. ${ }^{2}$ Arquiteta e Urbanista, Mestre e Doutora em Arquitetura e Urbanismo, Docente do curso de Arquitetura e Urbanismo da Universidade do Oeste Paulista - UNOESTE.

\section{RESUMO}

As áreas verdes e de lazer são componentes fundamentais para o bom funcionamento de uma cidade. Influenciam na convivência social e nos benéficos referentes à melhora do clima, resultando em um ambiente urbano agradável. Dessa forma, a qualidade de vida da população urbana é melhorada. Ao mesmo tempo, aspectos de mobilidade urbana também influenciam nessas questões, como o uso estimulado e facilitado da bicicleta. Por meio dessa visão, foi elaborado estudo de caso na cidade de Anaurilândia, no interior do estado do Mato Grosso do Sul, de pequeno porte, que apresenta, atualmente grande carência de vegetação urbana. Busca-se diretrizes de projeto para mitigar seus aspectos negativos intra-urbanos por meio da implantação de novas áreas verdes e da ligação dessas às existentes, com o uso das ciclovias.

Palavras-chave: Áreas verdes, Mobilidade Urbana, Arborização, Ambiente Urbano, Meio Ambiente Urbano.

\section{INTRODUÇÃO}

Este trabalho é resultado de pesquisas elaboradas para trabalho de conclusão de curso em Arquitetura e Urbanismo, na Universidade do Oeste Paulista. O tema escolhido é a interligação física de áreas verdes urbanas na cidade de Anaurilândia-MS, visando a uma melhora nas condições climáticas e ambientais, além unificar a malha da cidade por meio de tipologias de mobilidade e acessibilidade urbanas, estimulando a redução de utilização de automóveis.

Essa intervenção tem como problemática a perda cada vez maior dos recursos naturais causada pela crescente urbanização das cidades e o aumento gradativo da população, afetando principalmente a vegetação e acarretando em grandes transformações na estrutura das cidades.

A diminuição de áreas verdes urbanas resulta em sérios danos á população, como o aumento da temperatura, a redução de áreas de lazer e recreação, e a falta de conservação da natureza. Desta forma a pesquisa justifica-se por abordar a temática das áreas verdes, locais que possuem algum tipo de vegetação em sua essência; entretanto para assim serem consideradas deveriam ter uma predominância da vegetação, com 70\% da área total (MAZZEI; COLESANTI; SANTOS, 2007).

A vegetação interfere drasticamente sobre os elementos climáticos, tendo grande contribuição no controle da radiação solar, na temperatura ambiental, na umidade do ar, na ação dos ventos e da chuva, além de amenizar a poluição. Tornando-se assim, elementos indispensáveis 
ao bom funcionamento do meio ambiente. Na escala urbana o uso da paisagem natural é responsável por melhorar as condições sonoras, a temperatura, servindo também como ornamentação, colaborando também com a economia de energia. (MASCARÓ, 1996).

A praça, sendo um espaço com muitos significados e com uma ambiência própria, possui alto conteúdo simbólico, com características que resultam em uma noção de lugar para as pessoas que a circundam e com forte ligação ambiental (MASCARÓ, 1996).

Para melhor entendimento dessa apropriação da natureza nos ambientes urbanos pelos agentes produtores do espaço, Henrique (2005) fez uma divisão em períodos históricos, nos quais o primeiro consiste no conhecimento da natureza como fruto da imaginação e contemplação, representada pela cidade grega; o segundo é marcado por uma interpretação bíblica, representada pelas cidades feudais, separadas da natureza por muros; o terceiro é referente às viagens marítimas, com a saída das muralhas, quando houve uma aproximação da natureza; o quarto é marcado pela incorporação da natureza à vida social, vendo-a como fonte de recurso; e o quinto e atual consiste em uma maior relação entre homem e natureza.

A história possui forte influência no que se entende hoje como áreas verdes. Assumindo a posição de praças, estão presentes no Brasil desde os primeiros anos de colonização, locados principalmente em pontos de destaque, com focalização urbanística, pontos com grande concentração populacional.

Os espaços verdes com o decorrer dos anos vêm como uma consequência das necessidades da população, além de reflexo de seus gostos e costumes (LOBODA e DE ANGELIS, 2009). No entanto com o passar dos anos, os anseios da humanidade começaram a ultrapassar a capacidade de regeneração da natureza, causando fortes impactos ambientais.

Os impactos ambientais são classificados como qualquer alteração produzida pelos homens e suas atividades com relação ao ambiente, que excedam sua capacidade de absorção. Considerando ambiente urbano como a relação entre homem, espaço construído e natureza; temos o espaço construído como resultante da transformação do ambiente para se adequar as necessidades da aglomeração e para transformá-lo em habitat para a população.

O estreitamento dessas relações, com a proximidade física entre natureza e espaço construído, desrespeitando o gradiente estabelecido, acaba por ultrapassar os limites dos impactos ambientais significativos (MOREIRA, 1999). 
A degradação ambiental está presente principalmente em regiões com urbanização crescente. Essa deterioração é resultado principalmente da precariedade dos serviços e da omissão do poder público na proteção das condições de vida e reflexo do descaso da população (JACOBI, 1993).

Verifica-se a crescente necessidade em normalizar a relação entre homem e natureza, trazendo-a como aliada para o bom desenvolvimento do meio urbano, com o intuito de estabelecer áreas verdes como essenciais ao funcionamento das cidades, por meio de seus fortes benefícios a sociedade e melhorando também o seu funcionamento.

Essa junção entre o urbano e a vegetação deve vir agregada à redução dos impactos ambientais que possuem como uma das causas o uso do automóvel, meio de transporte cada vez mais utilizado e valorizado sobre os demais; acredita-se que devido à relação entre distância e tempo.

O automóvel se desenvolve no urbano, e que apesar de ser algo individualizado e de propriedade privada, faz parte do âmbito público, e suas consequências atingem toda a esfera populacional. Os processos de modernização resultam em uma homogeneização das práticas sociais, sendo que o uso do carro, além disso, homogeneíza também o espaço e o tempo, e penetra no cotidiano, fazendo parte de todas as esferas da vida (SCHOR, 2012).

As ações do uso do automóvel na vida da cidade atingem tal forma, que elas passam a se moldar em função do mesmo e suas consequências geram malefícios tanto para o meio ambiente quanto para a convivência em sociedade. Desta forma deve ser estimulado o uso de outros meios de transporte como o coletivo e as bicicletas.

A bicicleta assume a solução mais barata e prática aos problemas ambientais e também a redução do trânsito caótico, tendo benefícios à sociedade ao todo. Mesmo sendo uma das melhores alternativas é pouco utilizada devido à falta de estrutura urbana, sendo que na maioria das cidades as vias são voltadas para o tráfego de motorizados, restringindo seu uso (DUARTE; SÁCHEZ; LIBARDI, 2008).

Apesar de a bicicleta ser um veículo muito frequente numericamente no Brasil, isso não se reflete na prática, pois na preferência para a mobilidade ela não aparece como uma da alternativa mais habitual, por se deparar com uma série de dificuldades na circulação, referentes ao conforto e à qualidade. A realidade atual é uma cidade com forte segregação, devido à capacidade inadequada dos espaços viários em compor mutuamente a quantidade de meios motorizados e pessoas que realizam seu deslocamento a pé ou de bicicleta (CHAPADEIRO, 2011). 
Para que a ideia de retomada da bicicleta como meio de transporte, e não apenas como forma de lazer, o que vem ocorrendo nas cidades brasileiras atualmente, é necessária a reestruturação do planejamento, com a implantação de ciclovias ou ciclo faixas, permitindo assim seu uso em toda a extensão da cidade. Afirmado Chapadeiro (2011, p.3): "Essa nova mobilidade deve ser pensada como sendo mais humana segura e menos nociva ao meio ambiente".

As ciclovias consistem em faixas exclusivas para ciclistas que possuem certa divisão física de outros elementos viários, podendo ser faixas gramadas, marcações no piso ou bastões de separação (DUARTE; SÁNCHEZ; LIBARDI, 2008).

Outra causa dos impactos ambientais é a retirada da cobertura vegetal em favor da prática da agricultura, na qual a região centro-oeste, referente à localização do Mato Grosso do Sul, ocupa posição de destaque, concentrando o maior rebanho de bovinos de corte, expressiva produção de carne de aves e suínos, além da expansão do cultivo de lavouras (SALTON et al, 2005).

Assim as cidades da região centro-oeste apresentam carência de cobertura vegetal, sendo propícias e necessárias às práticas com características de conservação do meio ambiente.

\section{METODOLOGIA}

A metodologia seguida neste trabalho está baseada em aprofundamento teórico dos temas pertinentes à pesquisa, e levantamentos de campo na cidade de Anaurilândia-MS, identificando os espaços arborizados, de lazer e vazios urbanos, além dos aspectos de vegetação urbana e estrutura viária urbana.

\section{CARÊNCIAS AMBIENTAIS E SOCIAIS - PROPOSTA EM ANAURILÂNDIA-MS}

Anaurilândia é um município do interior do Estado do Mato Grosso do Sul, com população de 8.493 habitantes em 2007, e área de $3.395 \mathrm{~km}^{2}$ (IBGE, 2007). Sua localização geográfica e topografia plana resultam em clima bastante singular, mas que não é agravado por causa de sua pequena densidade e ocupação populacional, mas que pode ser piorado com seu processo de expansão territorial urbano.

Ela está situada próxima ao rio Paraná, cujos afluentes se encontram em grande parte na região sul e a oeste, sentido ao qual deveria haver o desestimulado da expansão, devido ao fato da apropriação humana dessas áreas suscitar de forma negativa. (GORSKI, 2010). Podendo também possuir resultantes negativos a população ali residente, pois contribuem na formação de locais 
propícios a inundações, à insalubridade e ocorrência de solos de baixa resistência. (PERES, POLIDORI, 2011). Entretanto o princípio em questão foi desconsiderado.

Sua expansão que se deu de forma descontínua e desordenada, expandindo sua malha para diversos pontos, com formatos e tipologias distintas. Há advercidades relacionadas com a proximidade da rodovia, havendo a presença de um anel viário responsavel pela separação do bairro central dos demais.

Em sua maioria, a cidade cresceu de forma a suprir a necessidade de habitação sicial, que por sí só já são responsáveis por uma segregação urbana, esta causada pela separação e concentração das diferentes classes sociais na malha urbana, por serem áreas de forte homogeneidade social e também de uso, fato também presente na concentração do comércio na zona central da cidade (VILLAÇA, 2012). Ainda nessa região há a presença de vazios urbanos e terrenos baldios, o que cria problemas como o aparecimento de animais indesejados e possíveis focos de doenças, além de ser propício a práticas ilícitas.

A topografia pouco acidentado respalda uma maior facilidade de acesso, principalmente por veículos não motorizados, o que neste trabalho será explorado com a implantação de ciclovias.

Sendo considerada também a quantidade e a necessidade de áreas verdes, as já existentes gozam algumas particularidades negativas, nas quais ha escassez de práticas sociais. A cidade possui apenas duas praças, algumas áreas residuais e pequenos jardins nas áreas institucionais, em alguns deste há também certa arborização.

É comum á presença de arborização nas calçadas, notado uma falta de criterios e aplicação de conhecimentos técnicos, principalmente com a relação a escolha correta das especies e de seus locais adequados, o que ainda ocorre na maioria das cidades (NETO, SOUZA, 2011). Apresentando uma forte homogeneização, com escolhas equivocadas das especies, nas calçadas que possuem menor dimensionamento elas acabam por ocupar toda sua extensão.

Sendo que a cidade em questão possui um clima tropical úmido (IBGE). Essas regiões detêm uma variação de temperatura diária e estacional reduzida, com radiação intensa e umidade elevada (ROMERO, 2000). Nessas localidades os ventos são fracos, carecendo de recursos que aumentem o movimento do ar, tendo temperaturas e radiação elevada, há a necessidade de reduzir a absorção da radiação e a produção de calor, devido à quantidade de umidade deve ser evitada a absorção e promovida à evaporação. (ROMERO, 2001). 
Nas áreas urbanas pouco densas que possuem este tipo de clima deve haver a preocupação para com uma separação entre as construções e estas devem ser rodeadas por árvores, que proporcionem o sombreamento e a absorção da radiação.

Com relação às ruas estas devem dispor de um sombreamento que proporcionem a permanência no espaço público, sendo estabelecidos quando é lançado o traçado ou com a introdução de elementos como a vegetação, principalmente ao lado do poente, os portais, o alargamento de determinados trechos e as dimensões diferenciadas das calçadas, sendo necessária também a substituição das áreas pavimentadas em favor das gramadas (ROMERO, 2000).

Em estudos feitos por Kauffman, Machado, Barroso (2001, apud SHAMS, GIACOMELI, SUCOMINE, 2009) a respeito do conforto térmico em áreas abertas de clima quente e úmido, os resultados comprovam que a vegetação, principalmente de grande porte, possui um importante papel na modificação e amenização do clima, sendo que o sombreamento constitui em um dos elementos fundamentais para o conforto em climas tropicais.

Com relação ao uso da população nas áreas públicas é importante destacar sua origem relacionada à extração da erva mate, que é o principal elemento para o preparo de uma bebida típica do estado do Mato Grosso do Sul, o tereré, consumido principalmente nos finais de tarde nas calçadas em frente às residências.

Ainda relacionado ao uso do espaço público, as bicicletas consistem em uma das melhores opções, se não a melhor, de mobilidade urbana, servindo também como um combate à pobreza, que conforme Gomide (2003, p.27) "Uma política de combate à pobreza urbana e de inclusão social deve priorizar o transporte coletivo e o não-motorizado (a pé e por bicicletas) em detrimento do individual."

E, Anaurilândia, por ser uma cidade de pequeno porte e possuir uma declividade pouco acentuada e grande parte da população ser de baixa renda, o meio de transporte mais utilizado é a bicicleta.

A partir de todas as análises, foi possível configurar diretrizes mais adequadas para implantação das áreas verdes nessa cidade. as áreas para a implantação serão subdividido com relação a sua origem e a função que passará a exercer na malha urbana.

As áreas verdes já existentes, incluindo as residuais que serão reestruturadas e adequadas de forma a serem parte integrante da grade verde. Os terrenos baldios que apresentam tamanho e formas adequadas a tal implantação, buscando uma redução dos problemas gerados pelos 
mesmos, além de proporcionarem uma distribuição mais homogênea, por estarem bem distribuidos na malha urbana.

As áreas livres na frente e ao redor dos edificios institucionais, onde há a formação de jardins, extensos arboreos ou áreas ermas, proporcionando uma melhora de usos e também da vegetação. $E$, as calçadas que possuem maior dimensão, que para tal havera uma reestruturação das vias que passam por estas e desta forma terão a função de servir como elo das demais áreas, servindo como fechamento das áreas verdes e proporcionando uma mobilidade concisa em todo ambito urbanos.

\section{CONSIDERAÇÕES FINAIS}

Por intermédio dos estudos e análises feita sobre a cidade de Anaurilância-MS, com relação a suas características urbanas, sociais, econômicas e ambientais, com seus espaços públicos, relacionados à sua localização e uso, além de suas influências em todo o ambito urbano, foi possível determinar possíveis diretrizes para adequação e mitigação dos problemas identificados.

Assim sendo, os melhores locais e tipologia para a implantação das áreas verdes e, por conseguinte, sua forma de ligação puderam ser observadas, resultando na formação de uma malha unificada na cidade, facilitando o deslocamento e melhorando o clima urbano. O projeto específico de implantação e desenho urbano será elaborado a partir deste semestre (2/2013), em continuação ao trabalho de conclusão de curso.

Busca-se, desa forma, possibilitar discussões a respeito do prosseguimento do trabalho e da formulação da proposta.

\section{REFERENCIAS}

CHAPADEIRO, F.C. Limites e potencialidades do planejamento cicloviário: um estudo sobre a participação cidadã. 2011. Dissertação (Mestrado em Transporte). Universidade de Brasília.

DUARTE, F.; SÁNCHEZ, K.; LIBARDI, R. Introdução à mobilidade urbana. Curitiba: Juruá Editora, 2008.

GORSKI, M. C. B. Rios e cidades: Ruptura e reconciliação. São Paulo: Editora Senac. 2010.

GOMITE, A.A. Transporte urbano e inclusão social: Elementos para políticas públicas. Brasília: IPEA, 2003.

JACOBI, P. A percepção dos problemas ambientais urbanos em São Paulo. São Paulo: USP, 1993. 
<http://www.scielo.br/scielo.php?script=sci_arttext\&pid=S010264451993000300003\&lng=pt\&nr $\mathrm{m}=$ iso $>$. Acesso: 6 de agosto 2012.

KOHLER, M.C.M. et. al Áreas verdes no município de São Paulo: Análises, tendências e perspectivas. XXVI CONGRESSO INTERAMERICANO DE ENGENHARIA SANITÁRIA E AMBIENTAL, 2000.

LOBODA, C., DE ANGELIS, B. Áreas verdes públicas urbanas: conceitos, usos e funções. AMBIÊNCIA, set.2009. Disponível em: <http://revistas.unicentro.br/index.php/ambiencia/article/view/157/185.> Acesso em: 15 nov. 2012.

MASCARÓ, L. Ambiência urbana. Porto Alegre: Sagra, 1996.

MAZZEI, K; COLESANTI, M.T.M.; SANTOS, D.G. Áreas Verdes Urbanas, Espaços Livres para o Lazer. Revista Sociedade e Natureza, Uberlândia, 2007.

NETO, E.M.L.; SOUZA, R.M. Comportamento e características das espécies arbóreas nas áreas verdes públicas de Aracajú. Scientia Plena, v. 7, n. 1, 2011. Disponível em: <http://www.scientiaplena.org.br/ojs/index.php/sp/article/viewFile/91/100>. Acesso em: 5 maio 2013.

PERES, O.M., POLIDORI, M.C. Simulação de crescimento, morfologias e o papel da hidrografia na dinâmica de expansão urbana. XII Conferencia Iberoamericana. Pelotas: Universidade Federal de Pelotas, 2011. Disponível em: <http://www.inegi.org.mx/eventos/2011/conf_ibero/doc/ET413_Peres.pdf>. Acesso em: 10 março 2013.

ROMERO, M.A.B. A arquitetura bioclimática do espaço público. Brasília: Editora Universidade de Brasília. 2001.

ROMERO, M.A.B. Princípios bioclimaticos para o desenho urbano. 2 a Ed. São Paulo: Pro Editores. 2000.

SALTON, J.C et al. Matéria Orgânica do Solo na Integração Lavoura-Pecuária em Mato Grosso do Sul. Dourados: Embrapa, 2005.2 Disponível em: <http://ag20.cnptia.embrapa.br/Repositorio/BP200529_000gthayx4t02wx7ha087apz2uz15bm3. pdf> Acesso em: 20 nov. 2012.

SCHOR, T. 0 automóvel e o desgaste social. São Paulo Perspec., v. 13, n. 3, 1999 . Disponível em: $<$ http://www.scielo.br/scielo.php?script=sci_arttext\&pid=S01028839 1999000300014\&lng=en\&nrm=iso>. Acesso em 15 nov. 2012.

SHAMS, J.C.A., GIACOMELI, D.C., SUCOMINE, N.M. Emprego da arborização na melhoria do conforto térmico nos espaços livres públicos. REVSBAU Piracicaba - SP, v.4, n.4, p.1-16, 2009. Disponível em: <http://www.revsbau.esalq.usp.br/artigos_cientificos/artigo71.pdf>. Acesso em: 5 abril 2013. 
SOUSA, M.T.R.; MACHADO, R. Os parques urbanos e a cidade sob a abordagem do turismo e do planejamento dos transportes. Gaia Scientia - UFPB. v.1, n.2, 2007. Disponível em: <http://periodicos.ufpb.br/ojs/index.php/gaia/article/view/2273>. Acesso em: 12 abril 2013.

VILLAÇA, F. Espaço intra-urbano no Brasil. 2a Ed. São Paulo: Studio Nobel, 2001. 